\title{
Oral Naltrexone Treatment for Cholestatic Pruritus: A Double- Blind, Placebo-Controlled Study
}

\author{
FRANK H. J. WOLFHAGEN, ${ }^{*}$ EMILIO STERNIERI, ${ }^{\ddagger}$ WIM C. J. HOP, ${ }^{\S}$ GIOVANNI VITALE, ${ }^{\ddagger}$ \\ MARCO BERTOLOTTI, ${ }^{\ddagger}$ and HENK R. VAN BUUREN*
}

*Department of Hepatogastroenterology, University Hospital Rotterdam-Dijkzigt, Rotterdam, The Netherlands; ”Department of Clinical Pharmacology, University of Modena, Modena, Italy; and ${ }^{\S}$ Department of Biostatistics, Erasmus University, Rotterdam, The Netherlands

Background \& Aims: The efficacy of currently available therapeutic agents for cholestatic pruritus is often disappointing. The aim of this study was to assess the antipruritic effect of naltrexone, an oral opiate receptor antagonist. Methods: Sixteen patients with pruritus of chronic cholestasis were randomized to receive naltrexone (4-week course of $50 \mathrm{mg}$ naltrexone daily) or placebo. Pruritus, quality of sleep, fatigue (using visual analogue scales), side effects, and liver function were assessed every 2 weeks. Serum naltrexone and $6 \beta$ naltrexol concentrations in all patients and 5 healthy controls were measured during the first day of naltrexone treatment. Results: Mean changes with respect to baseline were significantly different, in favor of the naltrexone group, for daytime itching ( $-54 \%$ vs. $8 \% ; P$ $<0.001)$ and nighttime itching $(-44 \%$ vs. $7 \%, P=$ 0.003 ). In 4 naltrexone-treated patients, side effects (transient in 3 cases) consistent with an opiate withdrawal syndrome were noted. No deterioration of the underlying disease was observed. Naltrexone and $6 \beta$ naltrexol levels did not differ between patients and controls, and there was no significant association with treatment response. Conclusions: For patients with cholestatic liver disease and itching, refractory to regular antipruritic therapy, oral naltrexone may be an effective and well-tolerated alternative.

$\mathbf{P}$ ruritus is a common and occasionally disabling symptom in patients with chronic cholestatic liver disease. Clinical experience over the last decades indicates that patients with pruritus may benefit from treatment with bile salt-binding resins ${ }^{1-5}$ or rifampicin. ${ }^{6,7}$ The efficacy of these agents is unpredictable, and side effects are not uncommon. ${ }^{5,8}$ The efficacy of a variety of other agents including antihistamines and ursodeoxycholic acid has not been demonstrated convincingly. ${ }^{9,10}$ In a minority of cases, itching may be so aggravating that other therapeutic modalities, including plasmapheresis, hemoperfusion, biliary drainage, and ultimately liver transplantation, are indicated. ${ }^{-4,11}$
Recent studies on the role of the central nervous system in cholestatic itching indicate that endogenous opiate substances of the enkephalin class, in particular, may be potential mediators. ${ }^{12,13}$ Accumulating evidence supports this theory: opiates have been found to induce naloxone-reversible pruritus ${ }^{14}$; plasma levels of enkephalins, which can pass the blood-brain barrier, ${ }^{15-17}$ are elevated in chronic cholestatic liver disease ${ }^{18-20}$ and in rats with a resected bile duct ${ }^{21}$; and naloxone reversible itching can be induced in monkeys by injecting plasma from cholestatic patients with pruritus into the medullary dorsal horn. ${ }^{22}$ Moreover, treatment with opiate antagonists (i.e., naloxone, nalmefene) of patients with primary biliary cirrhosis (PBC) has led to impressive amelioration of the itching. ${ }^{13,23-25}$ However, the drugs investigated have important limitations. Naloxone has a short half-life and can only be administered parenterally. Nalmefene treatment is associated with a severe opiate withdrawal-like ("cold-turkey") syndrome, ${ }^{13}$ and is currently available for experimental use only.

Naltrexone ( $N$-cyclopropylmethylnoroxymorphone), an opiate receptor antagonist that can be administered orally, is being used to treat opiate addiction. It is a structural analogue of naloxone and nalmefene with a bioavailability and half-life that lie between those of the former two. Naltrexone undergoes extensive $(95 \%)$ firstpass metabolism. The main metabolite is $6 \beta$-naltrexol, which exerts minimal but long-lasting opiate antagonist activity and reaches much higher plasma levels than the parent drug. Clearance is mainly via the renal route. ${ }^{26,27}$

We initiated a randomized, double-blind, placebocontrolled trial to assess the antipruritic effects and tolerance of naltrexone in patients with chronic cholestatic liver disease.

Abbreviations used in this paper: AUC, area under the curve; PBC, primary biliary cirrhosis; PSC, primary sclerosing cholangitis; VAS, visual analogue scale.

(C) 1997 by the American Gastroenterological Association 0016-5085/97/\$3.00 


\section{Materials and Methods}

\section{Patients}

On the basis of power calculations, 16 patients were included in this study: 13 with PBC, 2 with primary sclerosing cholangitis (PSC), and 1 with features suggesting PSC who refused to undergo diagnostic endoscopic retrograde cholangiopancreatography. All patients had persistent generalized pruritus without major fluctuations or symptom-free periods during the preceding 3 months. In all cases, the following conditions were excluded: use of opiates or deterioration of liver function test results during the last 3 months, renal failure (creatinine $>150 \mu \mathrm{mol} / \mathrm{L}$ ), changes in antipruritic medication (e.g., cholestyramine, rifampicin, antihistamines, ursodeoxycholic acid) within 1 month of entry, and pruritus primarily due to a nonhepatological disorder. Comedication could be continued unaltered.

The study was performed from March to December 1994 at the University Hospital Rotterdam. All patients were inhabitants of the Netherlands and gave written informed consent. The study was approved by the Medical Ethics Committee of the University Hospital Rotterdam.

\section{Design of the Study}

After a 2-week period in which baseline scores were obtained, patients were randomly assigned (using opaque envelopes) to receive capsules containing either $25 \mathrm{mg}$ naltrexone (Nalorex, Dupont Merck, Wilmington, DE) or placebo for 4 weeks. On the first day, medication was given in two doses of $25 \mathrm{mg}$, each 2 hours apart; subsequently, the patient received $50 \mathrm{mg}$ naltrexone or placebo once daily.

All patients were seen by the same physician (F.H.J.W.), twice before randomization and 2 and 4 weeks after the start of treatment. At each visit, the occurrence of adverse events, particularly withdrawal-like symptoms ${ }^{28}$ blood pressure, heart rate, and liver function (bilirubin, transaminases, alkaline phosphatase), were assessed. At the start and end of treatment, serum creatinine, albumin, and total bile salt levels and prothrombin time were measured.

Patients were admitted to the hospital during the first 8 hours (9 AM to 5 PM) of treatment for continuous monitoring of vital signs and adverse effects. Before the first dose, and at 2 (i.e., before the second dose), 4 , and 8 hours serum aliquots were drawn and stored at $-20^{\circ} \mathrm{C}$ until the concentrations of naltrexone and its major metabolite, $6 \beta$-naltrexol, could be assayed. Control data on naltrexone and $6 \beta$-naltrexol levels were obtained from 5 healthy controls ( 2 men; median age, 49 years; range, 30-60 years) who consented to take naltrexone for 1 day, according to the same schedule.

Drug assays were performed according to Zuccaro et al. ${ }^{29}$ with minor modifications using a Beckman System Gold High Performance Liquid Chromatograph equipped with a diode array detector module 168, set at $202 \mathrm{~nm}$ (Beckman Instruments Inc., San Ramon, CA). A reversed-phase C-18 25 cm $\times 4.6 \mathrm{~mm}$ Hypersil column (Labservice Analytical, Bologna,
Italy) packed with $5 \mu \mathrm{m}$ octadecylisilane was used. The area under the curve (AUC) of the plasma concentrations of naltrexone and $6 \beta$-naltrexol was calculated according to the trapezoidal rule, restricted to the time interval of experimental samples.

\section{Assessment of the Perception of Pruritus}

Throughout the study, patients scored the severity of pruritus each day on visual analogue scales (VAS). Separate scales for itching during the day (from awakening to going to bed) and night had to be completed before going to bed and after awakening, respectively. The scales were designed according to standard principles ${ }^{30}$ and consisted of $100-\mathrm{mm}$ horizontal lines, without marks, on which the patient was asked to indicate the severity of itching. The left side $(0 \mathrm{~mm})$ was labeled "no itching" and the right side $(100 \mathrm{~mm})$ "unbearable itching." Similar VAS were used for the quality of sleep (slept all night-no sleep at all; to be filled in upon awakening) and fatigue (no tiredness-severely tired; to be completed at bedtime).

\section{Statistical Analyses}

The mean of the values of the VAS scores for the 5 days preceding each visit was used for analysis of symptoms. Paired and unpaired $t$ tests or their nonparametric equivalents, where appropriate, were used. In addition to comparison of the two treatment groups, analysis of covariance was used to adjust for some differences in baseline characteristics. Correlations were determined by Spearman's rank correlation test (Rs). All analyses were performed according to the intention-totreat principle. A two-sided $P$ value of $\leq 0.05$ was considered significant.

\section{Results}

Baseline characteristics are presented in Table 1. In the naltrexone group, the liver function tests at entry seemed to be increased and the baseline pruritus scores were slightly higher compared with the placebo group. In the naltrexone group, the dose was decreased to 25 mg for 1 patient on the seventh day due to side effects, and 1 patient withdrew after 2 weeks because itching increased. The latter patient was subsequently treated with rifampicin, which resulted in a decrease in pruritus. Treatment compliance, assessed by pill counts, was $100 \%$.

\section{Effects on Symptoms}

Visual analogue scores for daytime and nighttime pruritus, quality of sleep, and fatigue are presented in Figures $1-4$. Table 2 shows the differences in percentage change in these variables after 4 weeks of treatment; all changes were greater in the naltrexone group than the placebo group. The changes in the pruritus scores were 
Table 1. Patient Characteristics at Entry

\begin{tabular}{lcc}
\hline & $\begin{array}{c}\text { Naltrexone } \\
(\mathrm{n}=8)\end{array}$ & $\begin{array}{c}\text { Placebo } \\
(\mathrm{n}=8)\end{array}$ \\
\hline Female/male & $7 / 1$ & $5 / 3$ \\
PBC/PSC/unclassifie & $8 /-/-$ & $5 / 2 / 1$ \\
Child -Pugh class A/B/C & $7 / 0 / 1$ & $7 / 1 / 0$ \\
Age $(y r)($ range) & $58(37-72)$ & $46(43-74)$ \\
Bilirubin (N, 14 $\mu$ mol/L) & $50(14-435)$ & $17(8-94)$ \\
Alkaline phosphatase & & \\
$\quad$ N, 75 U/L) & $410(256-583)$ & $187(64-512)$ \\
ALT (N, 30 U/L) & $72(22-302)$ & $77(7-80)$ \\
Serum bile salts & & \\
$\quad$ N, 10 $\mu$ mol/L) & $225(15-420)$ & $71(34-340)$ \\
Daytime pruritus (VAS) & $65(52-93)$ & $48(18-80)$ \\
Nighttime pruritus (VAS) & $59(8-92)$ & $47(7-80)$ \\
Scratch lesions & 7 & 8 \\
Previous antipruritic treatment & & \\
$\quad$ Ursodeoxycholic acid & $8(6)^{a}$ & $8(7)^{a}$ \\
Anion binders & $7(1)^{a}$ & 7 \\
Antihistamines & 3 & 3 \\
Rifampicin & 2 & 2 \\
Light therapy & 2 & 0 \\
Plasmapheresis & 1 & 0 \\
Other & 0 & 1 \\
\hline
\end{tabular}

NOTE. Results are expressed in number of patients or median (range). ALT, alanine aminotransferase; N, upper limit of normal.

${ }^{a}$ Treatment continued.

already significant at 2 weeks (all $P \leq 0.04$ ). When the values for the patient who discontinued therapy at 2 weeks were included at 4 weeks, the results did not change significantly. Adjustment for baseline differences in symptom scores, bilirubin, alkaline phosphatase, and serum bile salt levels as well as age did not have a major effect on these results; only the difference in the changes in fatigue failed to reach statistical significance after adjusting for these factors.

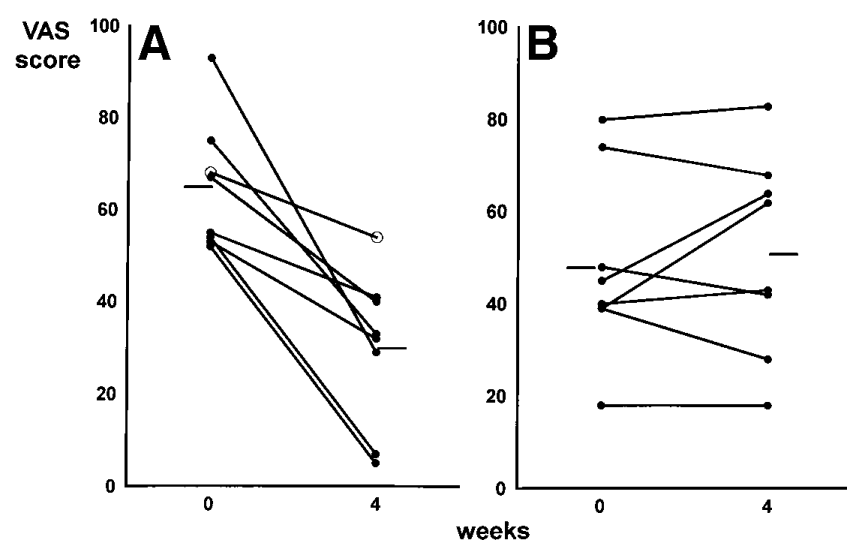

Figure 1. Severity of itching during the day for patients treated with $(A)$ naltrexone or $(B)$ placebo. Significan differences with respect to baseline were found for the treatment group only $(P=0.001)$. Horizontal lines indicate means. $\bigcirc$, Patient treated for 2 weeks.

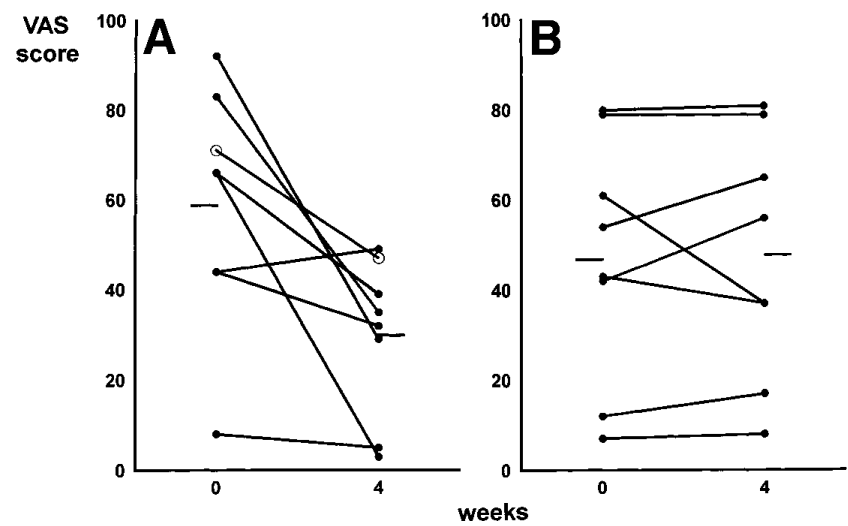

Figure 2. Severity of itching during the night for patients treated with $(A)$ naltrexone or $(B)$ placebo. Significan differences with respect to baseline were found for the treatment group only $(P=0.02)$. Horizontal lines indicate means. $\bigcirc$, Patient treated for 2 weeks.

In the naltrexone group, improvements in nighttime itching correlated well with the decrease in disturbed sleep $(\mathrm{Rs}=0.93 ; P<0.0001)$ and showed a trend with reduced fatigue $(\mathrm{Rs}=0.71 ; P<0.2)$.

For 5 of the 8 patients of the naltrexone group, the total pruritus score (i.e., the sum of the day and night scores) was reduced to half or less (the percentage decrease ranged from $49 \%$ to $93 \%$ ) after 4 weeks of treatment. Eventually, 2 patients were completely free of itching. In the placebo group, the maximum decrease was $21 \%$. The time of onset of the improvement in itching varied. For the 3 patients who exhibited the most dramatic results, the effect was already apparent during the first day, whereas in the other responders the effect gradually became apparent over a period of $1-3$ weeks.

\section{Side Effects and Safety of Treatment}

Four patients in the treatment group experienced an initial period of general malaise, associated with nausea (4 patients), dizziness (3), flushing (2), drowsiness (2), headache (1), nightmares (1), and tremor (1). These symptoms developed within the first 2 days and subsided or greatly improved after about 3 days, without additional treatment or withdrawal of medication. In 1 patient, the symptoms persisted and reduction of the dose to $25 \mathrm{mg}$ /day after 1 week provided some relief, but the symptoms did not disappear. Six patients (5 naltrexone, 1 placebo) reported mild abdominal cramps, which in general were present during the whole treatment period. Other symptoms noted were dry mouth (naltrexone, 2; placebo, 1), increased peripheral edema (naltrexone, 1), night-sweating (naltrexone, 1), irritability (placebo, 1), epistaxis (placebo, 1), and swelling of the hands (placebo, 
1). There were no significant differences between the two groups in changes in blood pressure or pulse rate.

A negative effect of naltrexone on the underlying liver disease did not occur as indicated by clinical changes or effects on serum transaminase, alkaline phosphatase, bilirubin, and bile salt levels.

\section{Plasma Levels of Naltrexone and $6 \beta$-Naltrexol}

Complete data on naltrexone and $6 \beta$-naltrexol levels were obtained for 6 patients. There were no differences between healthy controls and patients in naltrexone and $6 \beta$-naltrexol serum concentrations, summarized as the AUC for these compounds during the first 8 hours of therapy (Figure 5). Moreover, there were no correlations between the AUC for naltrexone or the $6 \beta$-naltrexol levels and changes in pruritus scores.

\section{Discussion}

This study shows that treatment with the oral opiate receptor antagonist naltrexone relieves the itching associated with cholestatic liver diseases. The reduction in itching is associated with an improved quality of sleep.

The observed difference at entry between the groups in bilirubin, serum bile salts, and alkaline phosphatase levels did not influence the outcome of this trial, as shown by analysis of covariance. These variables were not significantly related to either the baseline pruritus scores or the observed improvements. This is in agreement with literature data indicating that there is no clear relationship between itching and the severity of liver function abnormalities in cholestatic disorders, although the development of pruritus becomes more likely as jaundice progresses. $^{31-33}$

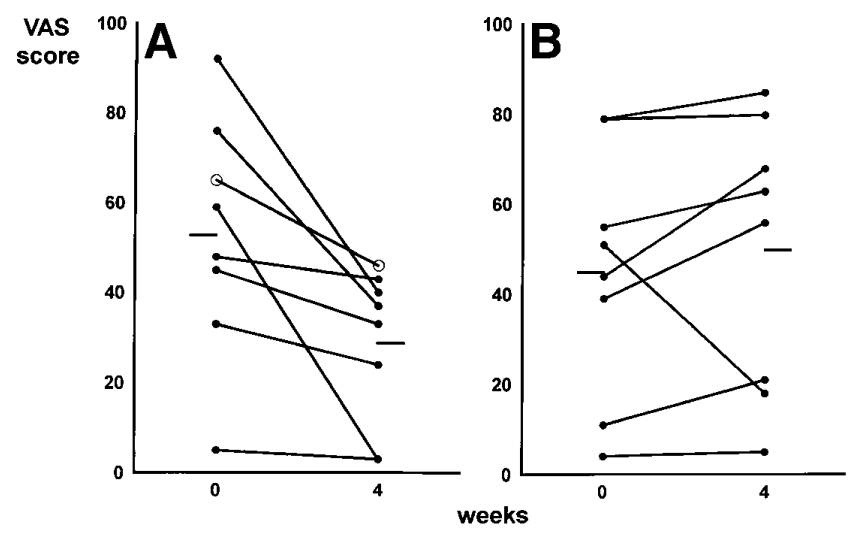

Figure 3. Severity of disturbed sleep for patients treated with $(A)$ naltrexone or $(B)$ placebo. Significan differences with respect to baseline were found for the treatment group only $(P=0.02)$. Horizontal lines indicate means. $\bigcirc$, Patient treated for 2 weeks.

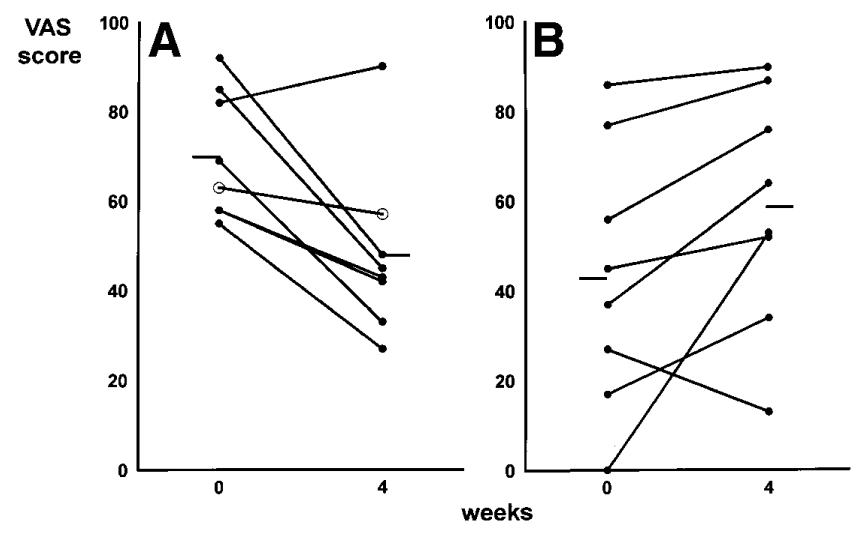

Figure 4. Severity of fatigue for patients treated with $(A)$ naltrexone or $(B)$ placebo. Significan differences with respect to baseline were found for the treatment group only $(P=0.01)$. Horizontal lines indicate means. $\bigcirc$, Patient treated for 2 weeks.

It has been suggested that the measurement of itching by VAS is inferior to more sophisticated and objective methods that quantify actual scratching activity. ${ }^{24}$ Apart from the practical difficulties of using these devices for ambulant patients during prolonged follow-up, we believe that the main goal of pruritus treatment is to improve the patient's well-being and quality of life, which only can be measured subjectively.

In this study, 5 of 8 treated patients suffered considerably less itching. One, however, experienced a recurrence of pruritus after an initial dramatic decrease. This has been observed occasionally by others during treatment with nalmefene (Bergasa NV, personal communication, May 1995) and naltrexone. ${ }^{34}$ One might speculate that during cholestasis, opiate receptors in the brain are downregulated due to enhanced opioid stimulation. The reverse, up-regulation of opiate receptors might occur during naltrexone treatment, resulting in an increased sensitivity to endogenous opioids. ${ }^{17}$ Carson et al. recently suggested that recurrence of pruritus can be prevented by interrupting treatment for 2 days every week. ${ }^{34}$

It is unclear why some patients respond to opiate receptor antagonists while others do not. Our data on serum naltrexone and $6 \beta$-naltrexol levels indicate that this is unlikely to be a result of impaired uptake or metabolism of naltrexone in cholestatic patients. Moreover, naltrexone exerts pharmacological effects in responders and nonresponders, as indicated by the occurrence of side effects in both groups. It seems unlikely that the naltrexone dose was too low. Heroin challenge and receptor binding studies have shown that a 50-mg dose of oral naltrexone provides sufficient opiate protection for 24 hours. ${ }^{26,35}$ Moreover, our preliminary experience with the administration of higher doses does not suggest a major enhancement of effect. 
Table 2. Percentage Change \pm SEM in VAS Scores at 4 Weeks Compared With Baseline

\begin{tabular}{llccr}
\hline & \multicolumn{2}{c}{$\%$ Change \pm SEM } & & \\
\cline { 2 - 3 } & Naltrexone & Placebo & & \\
& & & & \\
Itching & & & & \\
$\quad$ Daytime & $-54 \pm 10$ & $8 \pm 10$ & $62(32-92)$ & $0.001(0.042)$ \\
$\quad$ Nighttime & $-44 \pm 11$ & $7 \pm 9$ & $51(20-82)$ & $0.003(0.019)$ \\
Sleep disturbance & $-42 \pm 9$ & $22 \pm 16$ & $64(24-104)$ & $0.004(0.010)$ \\
Fatigue & $-31 \pm 8$ & $27 \pm 18$ & $58(14-102)$ & $0.01(0.23)$ \\
\hline
\end{tabular}

$\mathrm{Cl}$, confidenc interval.

${ }^{a} P$ values adjusted for age, baseline VAS, serum bilirubin, alkaline phosphatase, and bile salts are given in parentheses.

The results of the present study are consistent with those reported in one small, uncontrolled study with naltrexone ${ }^{34}$ and two placebo-controlled, crossover studies of 8 and 29 patients, respectively, on 24-hour naloxone infusions ${ }^{24,25}$; the latter yielded a reduction in itch perception of about $50 \%$. Two studies have suggested that nalmefene may be more powerful in relieving itching. ${ }^{13,23}$ However, the side effects seemed to be more severe and more frequent. In our study, half of the patients experienced side effects consistent with opiate withdrawal, ${ }^{13,28}$ but none of these symptoms led to treatment withdrawal; the symptoms had subsided to a large extent after the third day of treatment. Hemodynamic changes (i.e., increased blood pressure and decreased pulse rate, as noted in the British nalmefene study ${ }^{13}$ ) were not observed. Side effects generally developed during the second day of treatment, but the nalmefene-induced symptoms were apparent within 1 hour of the first dose. ${ }^{13}$ The differences in efficacy and side effects between naltrexone and nalmefene may be due to the longer half life and the higher receptor affinity and oral bioavailability of the latter. ${ }^{13,36-37}$

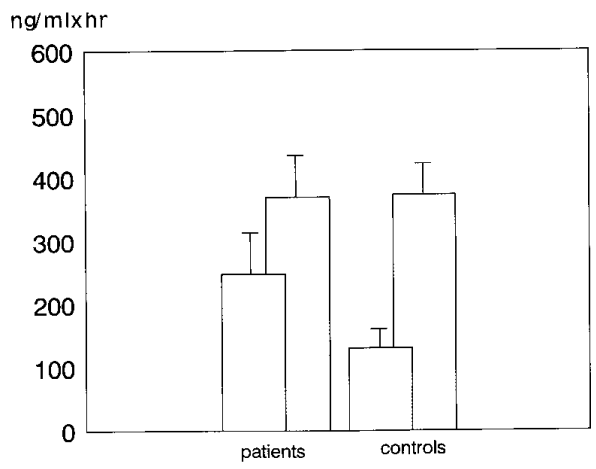

Figure 5. AUC for the concentrations of naltrexone (front bars) and $6 \beta$-naltrexol (back bars) during the firs 8 hours of naltrexone treatment for 6 patients and 5 healthy controls. Data given as mean + SEM. There were no significan differences between patients and controls.
In patients without hepatic disorders, high doses of naltrexone (300 mg/day), but not low doses ( $50 \mathrm{mg} /$ day), have been reported to induce liver function abnormalities. ${ }^{38}$ This was not observed in other studies for lower doses of naltrexone in patients with and without liver disease. ${ }^{39-41}$ We found no evidence of a negative effect of naltrexone on liver function. Thus, currently available data suggest that naltrexone can be administered safely to patients with liver disorders.

In conclusion, naltrexone seems to be an effective alternative for patients with cholestatic pruritus, which does not respond to other therapeutic modalities such as bile salt-binding resins, rifampicin, and antihistamines. The lack of response to naltrexone in some cases does not seem to be caused by impaired gastrointestinal absorption or metabolism of naltrexone. The long-term benefit/risk ratio for opiate receptor antagonist treatment remains to be established.

\section{References}

1. Garden JM, Ostrow JD, Roenigk HH. Pruritus in hepatic cholestasis. Arch Dermatol 1985; 121:1415 -1420.

2. Bergasa NV, Jones EA. The pruritus of cholestasis. Semin Liver Dis 1993; 13:319-327.

3. Khandelwal M, Malet PF. Pruritus associated with cholestasis: a review of pathogenesis and management. Dig Dis Sci 1994; 39:1-8.

4. Tygstrup N. Treatment of persistent itching secondary to biliary stasis. In: Dobrilla G, Bardhan KD, Steele A, eds. Nonresponders in gastroenterology. New York: Cortina-International Raven, 1991:195 -202.

5. Datta DV, Sherlock S. Cholestyramine for long-term relief of the pruritus complicating intrahepatic cholestasis. Gastroenterology 1966; 50:323 - 331 .

6. Ghent CN, Carruthers SG. Treatment of pruritus in primary biliary cirrhosis with rifampicin. Gastroenterology 1988; 94:488-492.

7. Bachs L, Elena M, Parés A, Piera C, Rodés J. Effects of longterm rifampicin administration in primary biliary cirrhosis. Gastroenterology 1992; 102:2077 -2080.

8. Girling DJ, Hitze KL. Adverse reactions to rifampicin. Bull World Health Organ 1979; 57:45 -49.

9. Duncan JS, Kennedy HJ, Triger DE. Treatment of pruritus due to chronic obstructive liver disease. Br Med J 1984; 289:22.

10. van Buuren HR, Wolfhagen FHJ, Schalm SW. Treatment with urso- 
deoxycholic acid, as monotherapy and in combination with other agents in primary biliary cirrhosis. In: van Berge Henegouwen GP, van Hoek B, de Groote J, Matern S, Stockbrügger RW, eds. Cholestatic liver diseases: new strategies for prevention and treatment of hepatobiliary and cholestatic liver diseases. Dordrecht, The Netherlands: Kluwer, 1994:236 -245.

11. Maddrey WC, Van Thiel DH. Liver transplantation: an overview. Hepatology 1988; 8:948 -959.

12. Bergasa NV, Jones EA. The pruritus of cholestasis: potential pathogenetic and therapeutic implications of opioids. Gastroenterology 1995; 108:1582 -1588.

13. Thornton JR, Losowsky MS. Opioid peptides and primary biliary cirrhosis. Br Med J 1988; 297:1501 -1504.

14. Jaffe JH, Martin WR. Opioid analgesics and antagonists. In: Gilman AG, Goodman LS, Rall TW, Marad F, eds. The pharmacological basis of therapeutics. 7th ed. New York: Macmillan, 1985: $491-531$.

15. Zlokovic BV, Lipovac MN, Begley DJ, Davson H, Rakic L. Transport of leucine enkephalin across the blood-brain barrier in the perfused guinea pig brain. J Neurochem 1987; 49:310 -315.

16. Banks WA, Kastin AJ, Fischman AJ, Coy DH, Strauss SL. Carriermediated transport of enkephalins and N-Tyr-MIF-1 across bloodbrain barrier. Am J Physiol 1986; 251:E477-E482.

17. Bergasa NV, Rothman RB, Vergalla J, Xu H, Swain MG, Jones EA. Central mu opioid receptors are down-regulated in a rat model of cholestasis. J Hepatol 1992; 15:220 -224.

18. Thornton JR, Losowsky MS. Plasma leucine enkephalin is increased in liver disease. Gut 1989; 30:1392 -1395.

19. Thornton JR, Losowsky MS. Plasma methionine enkephalin concentration and prognosis in primary biliary cirrhosis. Br Med J 1988; 297:1241 -1242.

20. Spivey JR, Jorgensen RA, Gores GJ, Lindor KD. Serum met-enkephalin levels in patients with primary biliary cirrhosis correlate with severity of disease but not pruritus (abstr). Gastroenterology 1992; 102:A892.

21. Swain MG, Rothman RB, Xu H, Vergalla J, Bergasa NV, Jones EA. Endogenous opioids accumulate in a rat model of acute cholestasis. Gastroenterology 1992; 103:630 -635.

22. Bergasa NV, Thomas DA, Vergalla J, Turner ML, Jones EA. Plasma from patients with the pruritus of cholestasis induces opioid receptor-mediated scratching in monkeys. Life Sci 1993;53: $1253-1257$.

23. Bergasa NV, Alling DW, Talbot TL, Chia SC, Souppaya M, Conjeevaram $\mathrm{H}$, Sallie R, Yurdaydin C, Wells M, Swain MG, DiBisceglie AM, Hoofnagle JH, Jones EA. Nalmefene therapy is associated with the relief of the pruritus of cholestasis: results of a doubleblind randomized placebo-controlled trial (abstr). Hepatology 1993; 18:177A.

24. Bergasa NV, Talbot TL, Alling DW, Schmitt JM, Walker EC, Baker $\mathrm{BL}$, Korenman JC, Park Y, Hoofnagle JH, Jones EA. A controlled trial of naloxone infusions for the pruritus of chronic cholestasis. Gastroenterology 1992; 102:544 -549.

25. Bergasa NV, Alling DW, Talbot TL, Swain MG, Yurdaydin C, Turner ML, Schmitt JM, Walker EC, Jones EA. Effects of naloxone infusions in patients with the pruritus of cholestasis. A double-blind, randomized, controlled trial. Ann Int Med 1995; 123:161-167.

26. Vereby K, Volavka J, Mule S, Resnick RB. Naltrexone: disposition, metabolism and effects after acute and chronic dosing. Clin Pharmacol Ther 1976; 20:315 -328.

27. Meyer MC, Straughn AB, Lo M-W, Schary WL, Whitney CC. Bio- equivalence, dose-proportionality, and pharmacokinetics of naltrexone after oral administration. J Clin Psychiatry 1985; 45:15 19.

28. Gold MS, Redmond DE Jr, Kleber HD. Clonidine blocks acute opiate-withdrawal symptoms. Lancet 1978; 2:599 -602.

29. Zuccaro PG, Altieri I, Betto P, Pacific R, Ricciariello G, Pini LA, Sternieri E, Pichini S. Determination of naltrexone and $6 \beta$-naltrexol in plasma by high performance liquid chromatography with coulometric detection. J Chromatogr 1991; 567:485 -490.

30. McCormack HM, De L'Horne DJ, Sheather S. Clinical applications of visual analog scales: a critical review. Psychol Med 1988; 18: $1007-1019$.

31. Mahl TC, Shockcor W, Boyer JL. Primary biliary cirrhosis: survival of a large cohort of symptomatic and asymptomatic patients followed for 24 years. J Hepatol 1994; 20:707 -713.

32. Rydning A, Schrumpf E, Abdelnoor M, Elgio K, Jenssen E. Factors of prognostic importance in primary biliary cirrhosis. Scand $J$ Gastroenterol 1990; 25:119-126.

33. Freedman MR, Holzbach RT, Ferguson DR. Pruritus in cholestasis: no direct causative role for bile acid retention. Am J Med 1981; 70:1011 -1016.

34. Carson KL, Tran TT, Cotton P, Sharara Al, Hunt CM. Pilot study of naltrexone to treat the severe pruritus of cholestatic liver disease. Am J Gastroenterol 1996; 91:1022 -1023.

35. Lee MCL, Wagner HN, Tanada S, Frost JJ, Bice AN, Dannals RF. Duration of occupancy of opiate receptors by naltrexone. J Nucl Med 1988; 29:1207 -1211.

36. Gal TJ, DiFazio CA, Dixon R. Prolonged blockade of opioid effect with oral nalmefene. Clin Pharmacol Ther 1986; 40:537 -542.

37. Dixon R, Howes J, Gentile J, Hsu HB, Hsiao J, Garg D, Weidler D, Meyer M, Tuttle R. Nalmefene: intravenous safety and kinetics of a new opioid antagonist. Clin Pharmacol Ther 1986; 39:49 53.

38. Allen Jl, Mitchell J, Knopman D, Levine S, Morley JE. High dose naltrexone and hepatic enzyme abnormalities (abstr). Gastroenterology 1985; 88:A1646.

39. Pini L-A, Ferretti C, Trenti T, Ferrari A, Sternieri E. Effects of longterm treatment with naltrexone on hepatic enzyme activity. Drug Metabol Drug Interact 1991; 9:161 -174.

40. Brahen LS, Capone TJ, Capone DM. Naltrexone: lack of effect on hepatic enzymes. J Clin Pharmacol 1988; 28:64 -70.

41. Hetrick WP, Krutzik MN, Taylor DV, Sandman CA. Naltrexone has no hepatotoxic effects in a self-injurious patient with chronic hepatitis. J Clin Psychopharmacol 1993; 13:453 -454.

Received January 9, 1997. Accepted June 16, 1997.

Address requests for reprints to: Henk R. van Buuren, M.D., Department of Hepatogastroenterology, University Hospital Rotterdam-Dijkzigt, P.O. Box 2040, 3000 CA Rotterdam, The Netherlands. e-mail: devlaming@inw2.azr.nl; fax: (31) 10-436-5916.

Supported by Lamepro Limited, Raamsdonkveer, The Netherlands. The authors thank the following physicians for referring their patients: Dr. R. A. F. M. Chamuleau, Academisch Medisch Centrum, Amsterdam; Dr. M. P. R. Cooreman, Academisch ziekenhuis St.Radboud, Nijmegen; Dr. Th. J. M. van Ditzhuijsen, Willem-Alexander Ziekenhuis, Den Bosch; Dr. O. A. Dobbenburgh, Het Nieuwe Spittaal, Zutphen; Dr. J.W. Kappelle, Medisch Centrum Leeuwarden; Dr. C. J. J. Mulder, Rijnstate Ziekenhuis, Arnhem; and Dr. M.H. Otten, Eemland Ziekenhuis de Lichtenberg, Amersfoort. 